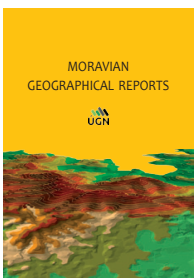

MORAVIAN GEOGRAPHICAL REPORTS

The Czech Academy of Sciences, Institute of Geonics

journal homepage: http:/www.geonika.cz/mgr.html

doi: https://oi.org/10.2478/mgr-2020-0020

\title{
A tale of two cities: The comparative chrono-urbanism of Brno and Bratislava public transport systems
}

\author{
Robert OSMAN $^{\text {a*}}$, Vladimír IRA ${ }^{\text {b,c }}$, Jakub TROJAN $^{\text {a }}$
}

\begin{abstract}
Time policies in urban environments are discussed in this article, including some difficulties in comparing such policies between cities and in an international comparison of urban times in general. In response to the need to systematise methodological approaches to the comparison of urban time policies, we offer a concrete solution in terms of a comparative chrono-urbanism. The main issues under consideration are the theoretical framings, systematic procedures and an empirical illustration comparing two urban times. The comparison serves as a tool for assessment, when one urban time becomes a criterion for another urban time. This approach is applied in the case of an international comparison of two similar cities - Brno (Czech Republic) and Bratislava (Slovak Republic). Their urban times are operationalised through the timetables of their public transport systems, the lines of which are conceived as the institutional carriers of urban time. Based on the analysis of timetables from 2016, we present a detailed description of urban times of Brno and Bratislava, as well as their comparison, which makes it possible to assess the time policies in both cities, as well as their implications for planning.
\end{abstract}

Keywords: time policy, urban time, comparative chrono-urbanism, urban planning, Brno (Czech Republic), Bratislava (Slovak Republic)

Article history: Received 20 May, Accepted 25 October 2020, Published 31 December 2020

\section{Introduction}

Following the Italian school of urban time planning and the French school of chrono-urbanism, this article discusses time policies. It responds to a situation when current academic research often describes urban time for only one city or offers a time comparison of several locations within one city but does not compare the times of different cities. This situation is interpreted as a lack of systematic methodological procedures, which would make the comparison of urban times possible. To answer this need, the authors set three goals in terms of theory, methodology and an empirical case study. At the theoretical level, this paper intends to conceptualise urban times in a way that enables mutual comparability of different urban times. Methodologically, a way to systematise comparison of the urban times of multiple cities during one moment in time, or one city in various time periods, is presented. To achieve these goals, we use a spectral analysis of rhythms, which is adapted for the comparison of the rhythmic profiles of institutional carriers of urban time. At the empirical level, the study aims to apply our approach in comparing the urban times of the cities of Bratislava (Slovakia) and Brno (Czech Republic).
Urban time is operationalised through the timetables of the city public transport systems, the lines of which are seen as the institutional carriers of urban time. The text thus describes the urban times of Bratislava and Brno, comparing them mutually, and shows how the approach of "comparative chrono-urbanism" makes it possible to assess the urban time of one city by the urban time of another city. This approach can contribute to a better understanding of time public policies applied in cities, and the importance of time policy and urban planning of city space in general. At the level of policies, the text follows some of the broader goals of chrono-urbanism, which criticise solely spatial tools of urban planning, and contributes to efforts at understanding "timing", or the common planning of city spacetime.

\section{Comparative chrono-urbanism}

\subsection{Time-geography and the multiplication of time}

The traditions of time geography inform our approach in this research and follow the original assumptions of the

\footnotetext{
${ }^{a}$ Department of Environmental Geography, Institute of Geonics of the Czech Academy of Sciences, Brno, Czech Republic (*corresponding author: R. Osman, e-mail: robert.osman@ugn.cas.cz)

${ }^{\mathrm{b}}$ Institute of Geography, Slovak Academy of Sciences, Bratislava, Slovak Republic

${ }^{\mathrm{c}}$ Department of Geography, Faculty of Education, University of South Bohemia in České Budějovice, Czech Republic
} 
Lund School. It nevertheless reflects the enormous shift that interest in time has experienced in geography since its earlier renown in the 1970s and 1980s. The tradition understanding local time as one of the most basic defining characteristics is rooted in the very origins of the Lund time-geography. Abandoning a homogeneous, universal, linear and somewhat "abstract" time and replacing it with local, heterogeneous, meaningful, fragmented discontinuous time, or the multiplicity of times, is linked to the so-called chrono-geography. Thrift and Parkes noticed that spacetime is not the same everywhere, but changes in its dependence on location and time. Instead of abstract spacetime, they proposed a so-called timed space, i.e. space formed by the way time is treated within it (Parkes and Thrift, 1978, p. 119). Timed spaces are structured by time into distinct locations (Parkes and Thrift, 1978, pp. 121-129). According to these authors, chrono-geography thus represents a more general concept than time-geography; time-geography is seen as a partial approach working only with abstract time and abstract space (Rämö, 1999).

In comparison to time-geography, chrono-geography is broader and encompasses all kinds and forms of time and space conceptions (Parkes and Thrift, 1980, p. 9; Harmoinen, 2003, p. 10). They also introduced the concept of para-time, which is understood as a kind of meta-time or super-time stressing what is common for all time conceptions. From this metatime, various temporalities are derived, such as universe time, life time, social time, biological time, psychological time, etc. (Parkes and Thrift, 1980, pp. 36-105). Thus, the universal status of abstract time is destabilised, and geography begins to perceive it critically as a concept which can take various forms. It ceases to be seen as one abstract time: there are many times and not all of them are one-way and linear flows. In such a situation, the conception of time is pluralised and times of very different forms can co-exist (hetero-temporality, multi-temporality, polyrhythmicity: see Hutchings, 2008; Klinke, 2013).

\subsection{Urban time in Italian literature}

In this paper, we focus mainly on one kind of time - urban time. This concept has been developed during the feminist struggle for a more equal temporal organisation of cities at the turn of the 1980s in northern Italy, when the feminist movement responded to dual lives and their temporal incompatibility. The concept of urban time is thus rooted in the conception of a double presence, which pointed out that women had to live two mutually separated lives: maternal life and work life (Balbo, 1978). The lack of coordination of these lives creates many temporal problems, barriers and conflicts, which affect a large part of society and are not treatable at an individual level. To solve this incompatibility of double lives of (not only) women, time policy started to use two different time concepts - urban time and social time. While the former describes societal timing of cities through institutions (opening and closing hours, lunch and other breaks in offices, schools, hospitals and shops, etc.), social time defines the temporal behaviour of urban society (socially established holidays, rituals, customs, traditions such as everyday getting up, eating, working, learning, shopping, etc.). These two conceptions of time, set in opposition to each other, enable us to capture moments of temporal incompatibility, when the social time of city dwellers cannot be linked to the urban time of city institutions (Bonfiglioli, 1997; Belloni, 1998; Mareggi, 2002). In this article we will not utilise the concept of social time, limiting our analysis to the concept of urban time. Most frequently, geography uses urban time when studying the temporality of urban retail (Kärrholm, 2009, 2012; Kärrholm et al., 2017; Fernandes and Chamusca, 2014; Mulíček and Osman, 2018; Osman, Mulíček and Seidenglanz, 2019), or city public transport (Mulíček, Osman and Seidenglanz, 2015, 2016). We follow in the steps of the second group, and study urban time represented by public transportation. This is, however, a decision for the purposes of this paper only. The use of our procedures is not limited to urban time in the form of public transport timetables, but can also be used for different concepts of urban time (retail opening hours, water consumption, electricity consumption, intensity of electronic transactions, etc.).

\subsection{Chrono-urbanism in French literature}

Chrono-urbanism can be regarded as one of the most influential time policies. Time policy or a policy of time has been gradually established mainly in European states. Nevertheless, chrono-urbanism is typical for southern European countries, such as Italy, France, Spain or Portugal. Drawing on the experience of Italian cities, it has developed into the form of time policy and the time government of cities mainly in France, where it is linked with the work of François Ascher and Luc Gwiazdzinski (within the expert discourse of Geography) and at present, it is actively used by the current Mayor of Paris, Anne Hidalgo, in the form of Plans for the "City of fifteen minutes" (Ville Du Quart D'Heure). The above-mentioned authors point out that urban planning is realised mainly through space tools such as the zoning plan, the regulation plan or the building permit, while most of the problems of contemporary city communities stem from temporal uncertainty, its transfer to the individual, the creation of individual strategies "just-intime", and the simultaneous management of multiple tasks. Therefore, Ascher calls for temporal planning and city time policy, saying:

\footnotetext{
"Public authority has a triple role in this area: it has to ensure equal access to public services for city inhabitants, who tend to have a more atypical and irregular time schedules. It has to offer or enable collective services that make it possible for economic activities and individuals to develop new rhythms and time schedules. And finally, it has to coordinate, or regulate private temporalities in the name of general interest, maximisation of external savings and fight against inequality." (Ascher, 1997, p. 121)
}

As time policy, chrono-urbanism thus tries to respond to the social inequalities connected to the general speeding up of society, the irregularity of everyday activities, uncertainty, an unforeseeable future, difficulties in planning, time stress, etc. (Ascher, 1997, 2001, 2008; Gwiazdzinski, 2014, 2015; Drevon, Gwiazdzinski and Klein, 2017; Gwiazdzinski, Maggioli and Straw, 2018). More generally, through the "timing" of contemporary tools of urban planning, it tries to deal with current social problems stemming from various forms of colonisation and the privatisation of times of city dwellers. For the purposes of this paper, chrono-urbanism is thus seen as policy dealing with urban time.

\subsection{Internationalisation of time policies and comparative chrono-urbanism}

The existence of a plurality or heterogeneity of diverse times offers the possibility of their mutual comparison. Most often, the times of different localities, usually within one city, are compared in this context (Wunderlich, 2007, 2008, 2010a, 2010b, 2013; Pafka, 2013; Osman and Mulíček, 2017). 
A whole range of studies compares times of different cultures, societies or states. It is also possible to refer to comparative studies of religions (Laguerre, 2003, 2004a, $2004 \mathrm{~b}, 2007,2010$ ) or comparative studies of the societal meaning of time for different nations of the world (Levine, 1997). Less attention has been paid to comparing times of different cities. In this context, Lefebvre's work on Writing on Cities has been of crucial importance, comparing the rhythmicity of Mediterranean and Northern European cities (Lefebvre, 1996). Lefebvre's analysis was not based on urban times, however, but on the "ensemble of rhythms" (Lefebvre, 1996, p. 230). Studies that compare the urban times of different cities are rare (Johansson and Kociatkiewicz, 2011; Schwanen et al., 2012; Kärrholm et al., 2017), as well as those comparing urban times of one city in different times (Mulíček, Osman and Seidenglanz, 2016) or different cities in different times (Cochoy, Hagberg and Canu, 2015). This can be partially attributed to the great heterogeneity of urban times, their local specificity and difficult comparability. Nevertheless, some texts attempt at such a comparison, and their essential source of inspiration is the "spectral analysis" of individual temporal components of urban time posited by Mike Crang:

"A multiplicity of temporalities, some long run, some short term, some frequent, some rare, some collective, some personal, some large-scale, some hardly noticed - the urban place or site is composed and characterised through patterns of these multiple beats." (Crang, 2001, p. 190)

This approach has been used, for example in comparing the urban times of Angers, Lisbon, Malmö and Porto, working with the opening times of shops (Kärrholm et al., 2017 ), and for the comparison of urban times in Brno city in 1989 and 2009 (Mulíček, Osman and Seidenglanz, 2010, 2016), which used public transport timetables. None of these studies, however, attempted to use a systematic unified approach comparing the urban times of "different" cities. Such a systematic approach could increase the number of studies and highlight the role of chrono-urbanism for contemporary urban communities. In this article, we respond to this situation and introduce a methodological approach that facilitates the systematic comparison of two urban times (either times of two different cities, or one city at different times), which we call 'comparative chronourbanism'.

\section{Methodology}

At the theoretical level, this article is framed by the concept of urban time. The main question is: In what way it is possible to compare the urban times of different cities, or what options for comparison are offered by the concept of urban time. What can this comparison tell us about each of the cities, their temporalities and ways of life? These questions are then formulated into a unified goal, trying to conceptualise the city as a temporal unit, which can be described and compared with other cities based on their temporal characteristics.

At the methodological level, the research is constituted by comparative methods and spectral analysis. It consists of a description of the urban times of two selected cities, which are subsequently decomposed - using spectral analysis - into respective urban rhythms, and urban times are compared at the level of these rhythms. Methodologically, the paper tries to answer the questions of how the spectral analysis of urban rhythms can be used for comparison of urban times, how urban times can be decomposed into urban rhythms and how these rhythms can then be compared. Under these explicitly formulated research questions, there is an implicit methodological goal to describe and illustrate by practical examples the application of spectral analysis for the comparison of the urban times of two (or more) cities.

At the empirical level, the comparison concerns the urban times of two concrete cities - Brno (Czech Republic) and Bratislava (Slovak Republic). For the purposes of comparison, two relatively similar cities were sought, so that they could be compared, yet different enough, so that certain differences in their urban times could be identified. These criteria were fulfilled by the capital city of the Slovak Republic - Bratislava, and the second largest city of the Czech Republic - Brno. Both cities are located in a similar cultural and geopolitical context, they share some part of common history, they used to co-exist in one state, they are of similar size (in 2017, Bratislava had 422,000 inhabitants and Brno 378,000), and their mutual distance is only 130 kilometres. On the other hand, there are many differences stemming from the fact that the cities have belonged to different states since 1993, and Bratislava became the capital of the newly established Slovak Repubic at that time.

The two selected cities are compared using the concept of urban time. For the purposes of this study, urban time was operationalised as the form of the temporality of public transport connections in Brno and Bratislava. This choice was primarily motivated by pragmatic reasons, such as the comparable size of the two public transport systems, the public availability of data about timetables and connections, and mainly the comparable structure of the data. Of course, urban times of the two cities could have been compared using data from other institutions, such as the temporality of retail, schools, restaurants, etc. From the reasons mentioned above, the temporality of public transport was chosen.

The timetables of all public transport lines were processed, using the decisive time-point of September $1^{\text {st }}, 2016$ - the date on which both public transport companies updated their timetables in relation to the end of summer holidays and the beginning of a new school year. This date was selected to analyse a "normal" part of the calendar year, normal meaning a "secular", working, not-holiday part of the year. We worked with timetables of all modes of public transport (except ships and trains, even though these were part of the innercity networks), namely the trams, trolleybuses, and buses. Neither of the two cities has an underground rapid transit system (metro). The initial analysis accounted for all tram, trolleybus and bus lines operating within the administrative boundaries of the respective city, and also lines having most stops within the city district, which connected nearby settlements with the cities of Brno and Bratislava. Lines with a majority of stops outside the administrative districts of Brno/Bratislava were not considered. Both day and night lines were analysed within this delimitation. Timetables were processed for working days as well as weekends, using a unified methodology for both cities.

In the case of lines which did not use day-specific timetables, the timetable for a non-specified working day was used. In the case of a line using day-specific timetables, only one day was used, in the following order: Wednesday, Tuesday, Thursday, Monday, Friday. Weekend timetables were processed in a similar way: in the case when a line did not specify weekend days, a general weekend day was used; in the case when it differentiated between Sunday and Saturday, only one of them was entered, in the order Saturday, Sunday. 
Data constructed in this way were entered into the analysis with the empirical goal of answering the research question: "How does urban time in Brno differ from urban time in Bratislava?" The analysis consisted of spectral analysis of absolute as well as relative frequencies of daily connections. To obtain a general idea, the initial analysis also compared total aggregated numbers of all lines per hour in Brno and Bratislava, using absolute numbers.

Subsequently, a more detailed comparison was carried out at the level of individual lines, when the frequencies were relativised in relation to the total number of daily connections on each line. The relativised data were recorded in diagrams and grouped according to the mutual similarity in the distribution of daily connection shares, creating types with specific rhythmic profiles. In this way, all lines were divided into respective types, for each city separately. Subsequently, comparison of the urban times of the two cities was made, based on the representation of these rhythmic line types in each of them. The detailed results of this spectral analysis are stated in the following section.

\section{Comparison of two urban times: The cases of Brno and Bratislava}

The comparison of urban times of the selected cities through spectral analysis is made possible by the similar size of population in both cities, and also by the similar scope of their public transport systems. In a basic comparison, public transport in Bratislava shows somewhat higher numbers than the public transport in Brno: on a working day, it operates 33 more lines and 531 more connections than in Brno, and on a weekend day, it has 27 more lines and 769 more connections. In general, we can say that Bratislava public transport system is more extensive than that in Brno. The difference is larger on Saturdays and Sundays, when Bratislava provides $64.8 \%$ of workday connections, while Brno only $56.7 \%$ of workday connections. On a workday, Brno reaches $90.9 \%$ connections compared with Bratislava, while on a weekend day, it is only $79.6 \%$ connections (see Tab. 1).

A similar picture is rendered by comparison of the daily distribution of public transport connections. Again, it can be said that both cities are very similar. The distribution follows almost identical curves, both on workdays and on weekends. Only during weekends is there a difference in the absolute number of connections in favour of Bratislava, for the daylight hours. The rhythm of a workday is almost identical, with two peaks and one gap. People in both cities awaken around 4:00 in the morning, they are awake very quickly, and the number of connections culminates around 7:00, forming not only the first peak but also the absolute daily maximum. Afterwards, the number of connections keeps falling until nine o clock, when it settles to a continuous level lasting from 9:00 to 12:00. In the afternoon, the number of connections increases again until its second maximum at 16:00, gradually declining afterwards until it reaches its night minimum - which both cities have between 1:00-3:00 in the morning.

When comparing the rhythmicity of a workday in the two cities, we can identify several differences. Firstly, it shows that the light or active part of a day as construed by the activity in public transport is longer in Bratislava, mainly due to the evening hours. Whereas the waking-up in both cities has a similar speed, Bratislava "goes to sleep" more slowly than Brno. Simultaneously, Bratislava indicates higher absolute numbers of connections during both peaks, and lower during the noon gap. A mildly more balanced distribution of connections can be thus identified in Brno. The situation on a weekend day is different. The public transport systems of both cities show a similar distribution of connections with a homogeneous number during the whole day. Nevertheless, Bratislava starts its days off significantly earlier and finishes later than Brno. During the active part of the day, it also offers 30 more connections per hour than Brno (see Fig. 1).

A different picture can be drawn, however, if we differentiate the connections according to modes of transport. Public transport in Brno and in Bratislava is realised via three main modes of transport: trams, trolleybuses and buses. In both cities, the largest of these is bus transport, but its importance varies. Brno has a more proportional distribution of all modes of transport (bus $45 \%$, tram $30 \%$, trolleybus 25\% connections) than Bratislava (bus 60\%, tram $20 \%$, trolleybus $20 \%$ connections). While the share of workday connections realised by buses between 4:00 and 22:00 in Bratislava does not drop below 50\%, and approaches $70 \%$ during the peaks, its share in Brno is higher than $50 \%$ only between $21: 00$ and $22: 00$, while being only $35-45 \%$ of all connections per hour during the light part of the day. Bus transport on workdays also has a different

\begin{tabular}{lrrrrrr}
\hline & \multicolumn{2}{c}{ Brno } & & \multicolumn{2}{c}{ Bratislava } \\
\cline { 2 - 3 } \cline { 5 - 6 } \cline { 5 - 6 } \cline { 5 - 6 } Number of tram lines & workday & weekend & & workday & weekend \\
\cline { 5 - 6 } Number of trolleybus lines & 11 & 10 & & 9 & 8 \\
Number of bus lines & 13 & 11 & & 13 & 13 \\
Number of night lines & 41 & 32 & & 67 & 50 \\
Number of lines in total & 11 & 11 & & 20 & 20 \\
Number of tram connections & 76 & 64 & & 109 & 91 \\
Number of trolleybus connections & 1,607 & 882 & & 1,011 & 641 \\
Number of bus connections & 1,307 & 611 & & 1,143 & 868 \\
Number of night connections & 2,282 & 1,357 & & 3,568 & 2,159 \\
Number of connections in total & 102 & 156 & & 107 & 107 \\
\cline { 6 - 7 } & 5,298 & 3,006 & & 5,829 & 3,775 \\
\hline
\end{tabular}

Tab. 1: Basic comparison of public transport system size in Brno and Bratislava Sources: Public transport timetables in Brno and Bratislava (both valid on $1^{\text {st }}$ September 2016) 
rhythm than other modes of transport in both cities. Trams or trolleybuses have a more balanced number of connections during the day, while bus transport is usually laid on in the two peak hours of working days - due to its easier summoning and withdrawal. Interestingly, in Bratislava the higher number of connections in peak hours as compared to the noon gap is achieved with buses, but in Brno, trolley buses are used as well (see Fig. 2).

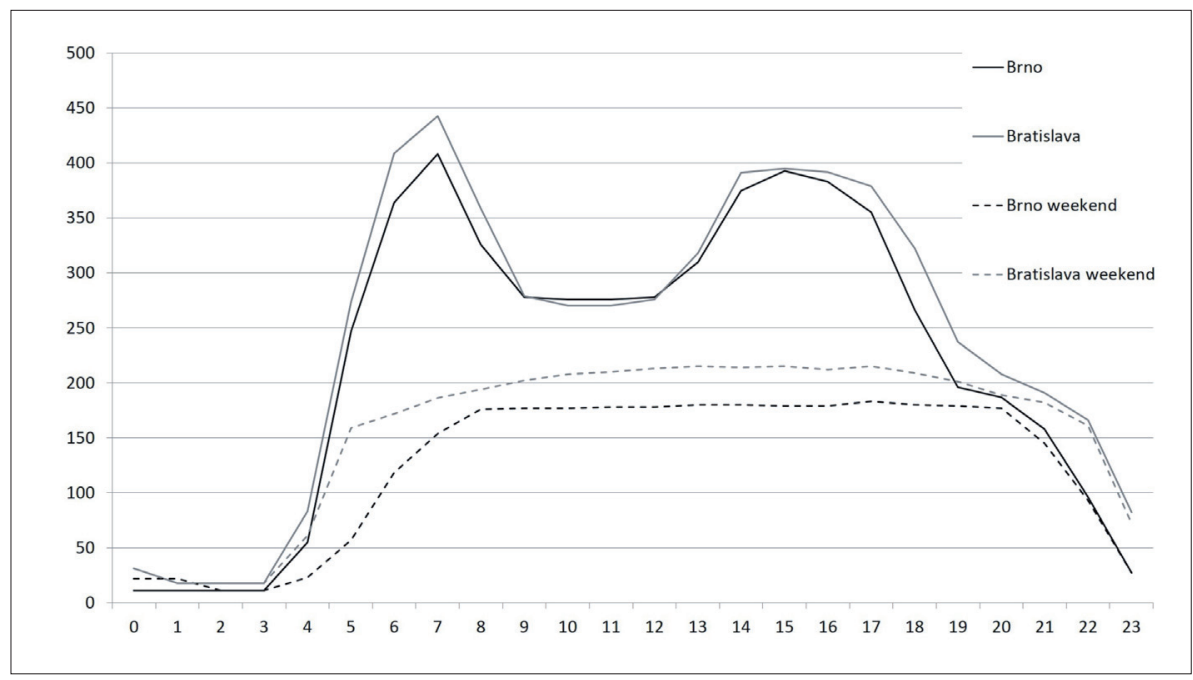

Fig. 1: The distribution of the total number of public transport connections in Brno and Bratislava during the course of the day. Sources: Public transport timetables in Brno and Bratislava (both valid on $1^{\text {st }}$ September 2016)

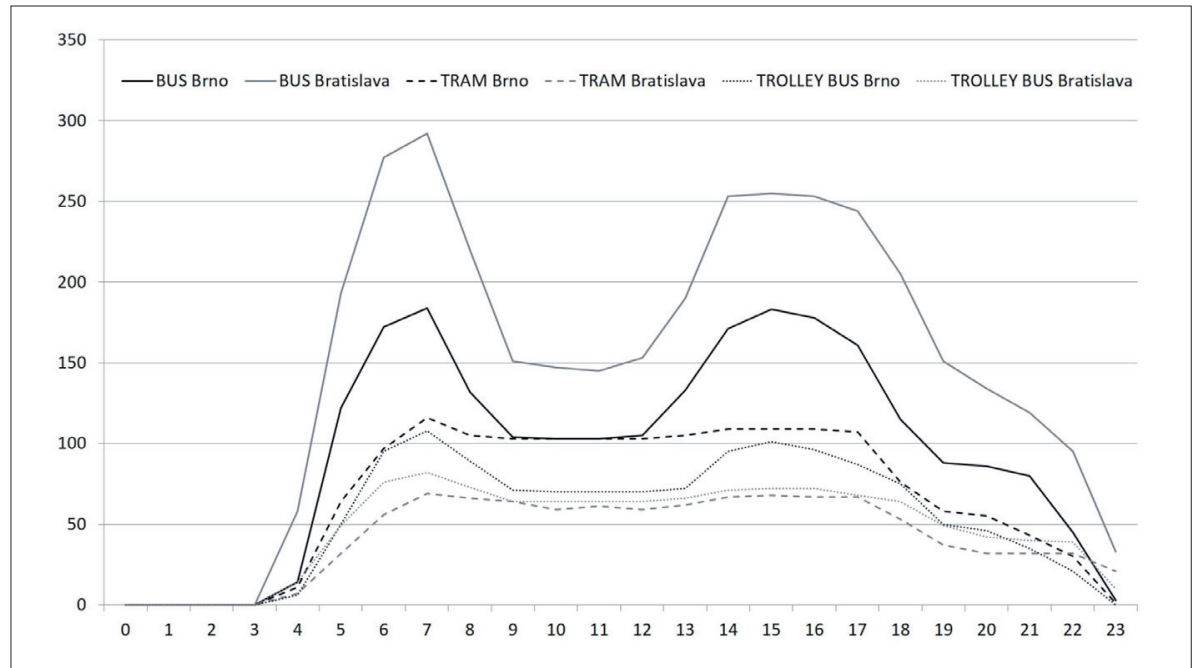

Fig. 2: The distribution of public transport connections in Brno and Bratislava on a workday - according to the mode of transport. Sources: Public transport timetables in Brno and Bratislava (both valid on $1^{\text {st }}$ September 2016)

The distribution of connections on a weekend day shows a different picture. All modes of transport have a proportional distribution during the day and vary only in their share in the total number of connections. As stated above, Brno decreases the number of connections more significantly than Bratislava, which highlights some of the differences between the two cities. This trend, however, is only visible in the case of bus and trolleybus transport. Both of these modes reach higher numbers in Bratislava, during a whole weekend day. Trams go against this trend and show higher number of connections - with the exception of early morning hours - in Brno (see Fig. 3).

When analysing the spatial layout of the respective modes of transport, knowing that tram lines are materially connected to the central parts of both cities, it is clear that the above-mentioned statement about Bratislava having more connections on a weekend day is not true in an absolute sense. There are more tram lines operating in Brno on a weekend day (10) than in Bratislava (8), which is also reflected in the number of tram connections Brno realises 241 more connections (882 in total) than Bratislava (641). While it is true that weekend public transport services in Brno are less frequent in general, its central parts serviced by trams are not affected by this cut in the number of connections. In Bratislava, the total decrease in connections is distributed more evenly across the whole city area, and in Brno it affects its non-central parts to a greater extent (see Fig. 4).

This brings us to the relativisation of the absolute number of connections, i.e. to the density of connections, or more precisely, the frequency of connections in a given area. To describe this aspect of urban rhythmicity, we chose the indicator of the average number of connections per line. While Bratislava clearly outnumbered Brno in the 


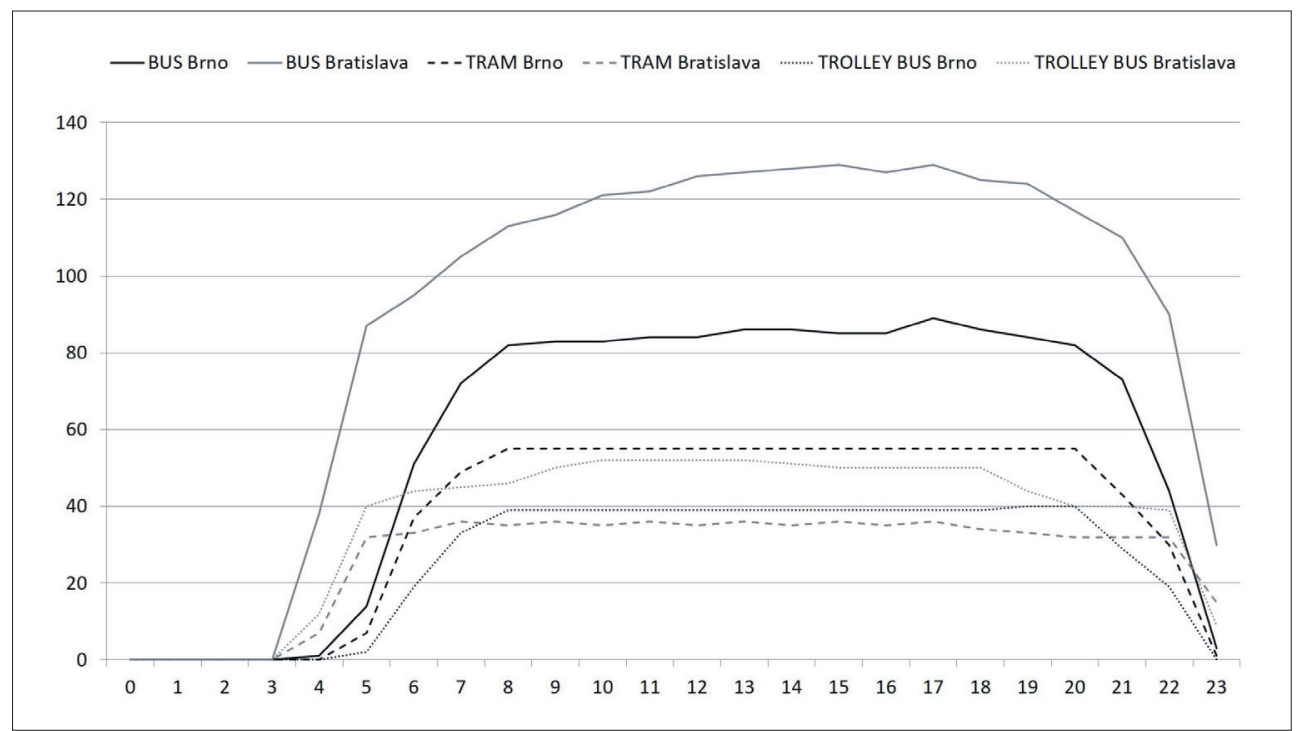

Fig. 3: The distribution of public transport connections in Brno and Bratislava on a weekend day - according to the mode of transport. Sources: Public transport timetables in Brno and Bratislava (both valid on $1^{\text {st }}$ September 2016)

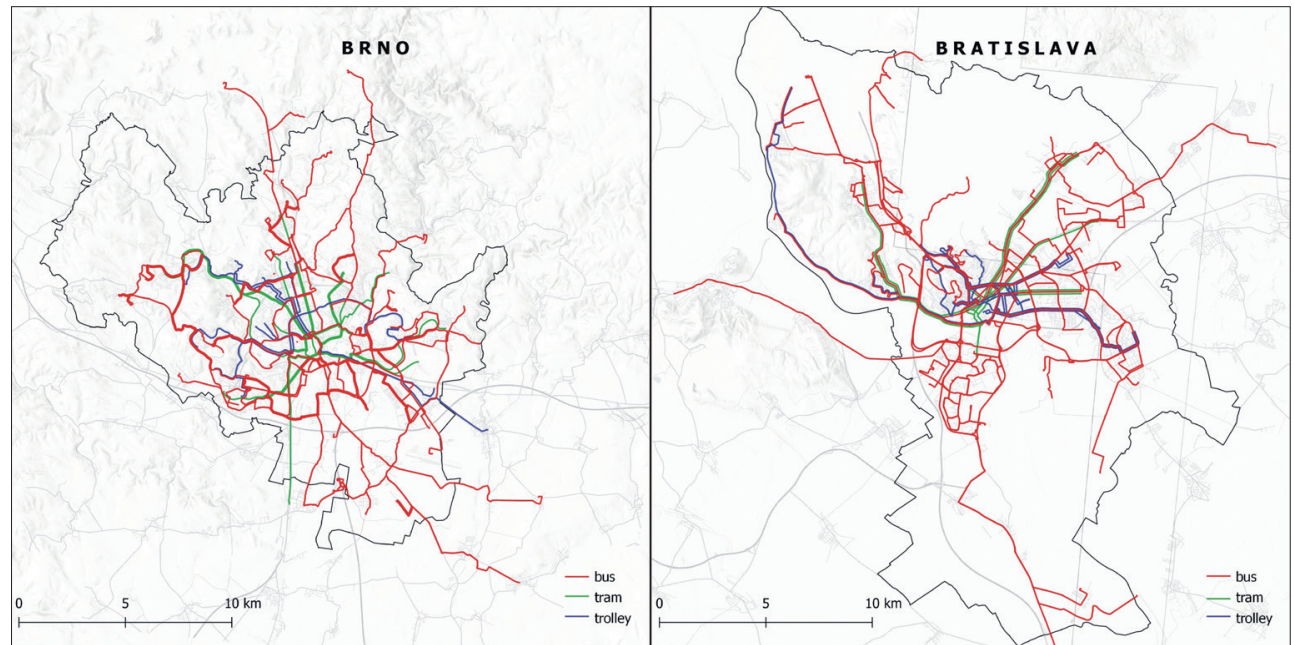

Fig. 4: The spatial layout of the modes of public transport in Brno and Bratislava

Source: authors' analysis

absolute number of connections, the number of connections per line shown by the relative indicator is higher in Brno. The disparity is higher on a workday, with Bratislava indicating the relative frequency of connections per line lower than Brno by 17 connections, while on a weekend day, this difference is only 6 connections in favour of Brno. On a workday, this difference is accounted for mainly by trams, with the average of 36 more connections per day per line, while on a weekend day, the difference in the relative frequency of connections can be ascribed to night lines.
Each city has a different organisation of night transport. Bratislava services use 20 nightlines, while in Brno it is only half the number; and in Bratislava, there is no difference between workdays and weekends as far as night services are concerned, but in Brno, weekend nights (or more precisely, nights before a day off) are serviced more frequently than workday nights. Generally, it can be summarised that Bratislava has a higher number of lines, which nonetheless have a lower average frequency of connections, both on workdays and on weekends (see Tab. 2).

\begin{tabular}{|c|c|c|c|c|}
\hline & \multicolumn{2}{|c|}{ Brno } & \multicolumn{2}{|c|}{ Bratislava } \\
\hline & workday & weekend & workday & weekend \\
\hline Average number of tram line connections & 146 & 88 & 112 & 80 \\
\hline Average number of trolleybus line connections & 101 & 56 & 88 & 67 \\
\hline Average number of bus line connections & 56 & 42 & 53 & 43 \\
\hline Average number of nightline connections & 9 & 14 & 5 & 5 \\
\hline Average number of connections per line & 70 & 47 & 53 & 41 \\
\hline
\end{tabular}

Tab. 2: The average number of daily public transport connections in Brno and Bratislava per line Sources: Public transport timetables in Brno and Bratislava (both valid on $1^{\text {st }}$ September 2016) 
If we look at the distribution of the average number of connections per line, we can see that Brno does not outnumber Bratislava at all times of the day. In the morning and in the evening, the number of connections per line is quite even in both cities, but some lines in Bratislava have a higher frequency. The lines in Brno are serviced more frequently during the daylight hours. On workdays between 6:00 and
18:00, Brno public transport offers at least one connection more than Bratislava per hour on all its lines. The largest difference is in the afternoon peak hours - between 15:00 and 17:00, the difference is 1.5 connections per hour per line. During weekends, the higher frequency is reached mainly between 7:00 and 21:00, on average 0.5 connections more per hour per line (see Fig. 5).

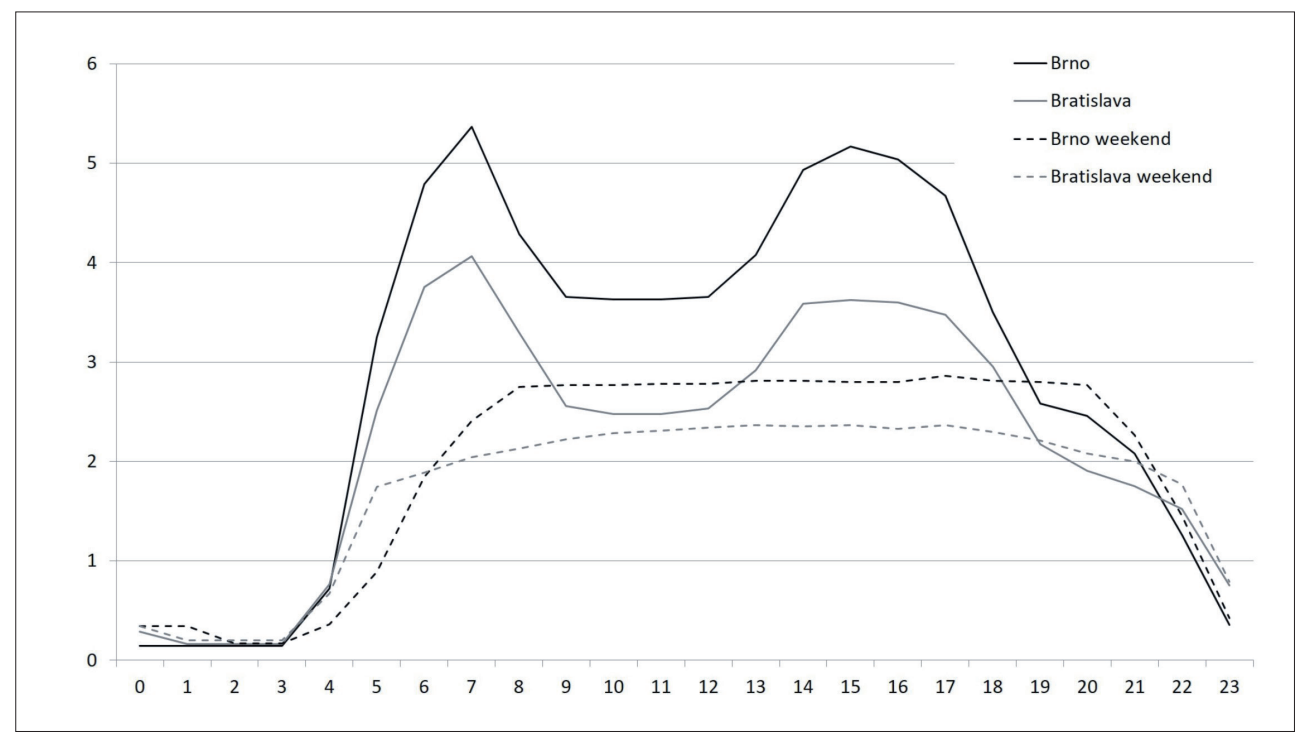

Fig. 5: The distribution of the average number of public transport connections per line per day in Brno and Bratislava Sources: Public transport timetables in Brno and Bratislava (both valid on $1^{\text {st }}$ September 2016)

Taking a more detailed look, both cities can be compared at the level of rhythmicity of their lines. A meaningful analysis, however, can be carried out only for workdays, when individual lines differ in their rhythmic profiles. Since there is a rather homogeneous distribution of all lines in both cities during weekends (Fig. 3), the rhythmicity of weekend days was not analysed. To be able to compare the rhythmic profiles of individual lines, the numbers of connections were relativised, counting the share $(\%)$ of connections operating on a single line in every hour (of the total number of connections at a given line). Due to the extreme fluctuation of low-frequency connections, further analysis considered only lines with more than 20 connections per day. This criterion ruled out 19 lines with the total number of 196 connections (3.7\% of all connections) in Brno and 34 lines with the total number of 340 connections (5.8\% of all connections) in Bratislava. Thus, the spectral analysis considered 57 lines of public transport in Brno and 72 lines in Bratislava.

The mere distribution of connections of all lines in both studied cities on a workday, however, did not bring results that can be easily interpreted (see Fig. 6). That is why spectral analysis was made based on the comparison of the rhythmic profiles of individual lines. This analysis resulted in four rhythmic line types for Bratislava, and 5 for Brno. Thus, four 'line types' with a comparable rhythmic profile were identified in both cities, and one more line type - not found in Bratislava - was discovered in Brno. Some of the analysed lines did not match any of the defined profiles: in Brno, two lines with 90 connections (1.7\% connections) did not correspond to any of the classified types, and in Bratislava, 4 lines with 101 connections (1.7\% connections) could not be classified. Rhythmic profiles of the four identified line types found in both cities are shown in Figure 7. The types are labelled as peak (A), homogeneous (B), morning (C) and industrial (D). Their detailed description is given in Table 3.

The most frequent type, i.e. the type comprising most lines in both cities, was the type with the peak rhythm (A). A peak rhythm means two strongly formed peaks with a clearly visible gap between them, while the number of connections

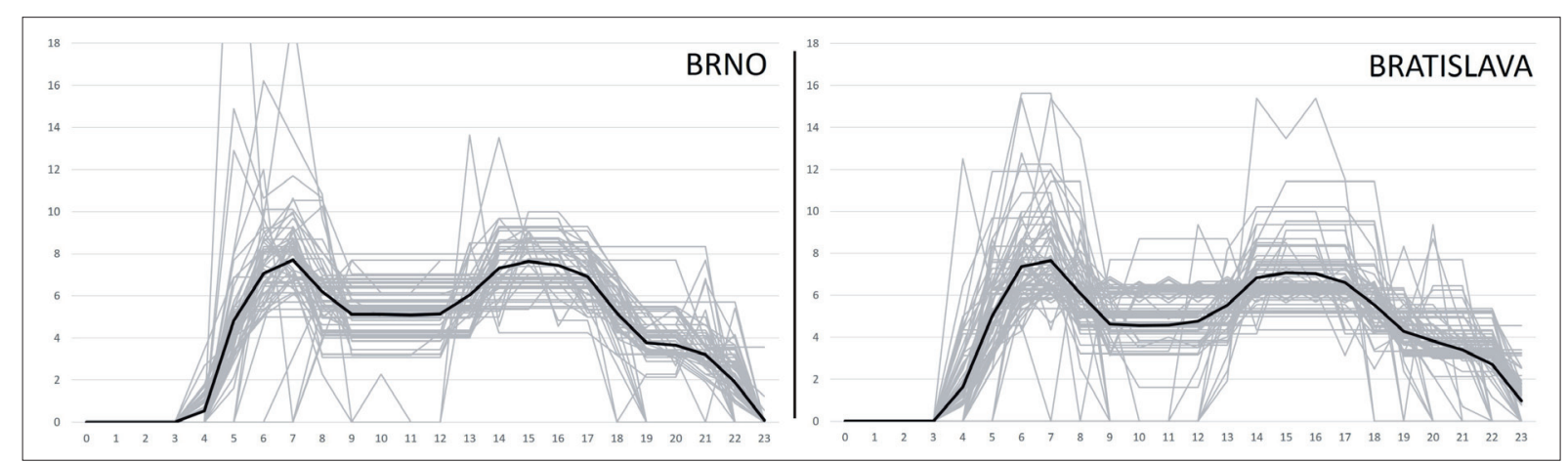

Fig. 6: The distribution of the relative number of connections of public transport lines on a workday Sources: Public transport timetables in Brno and Bratislava (both valid on $1^{\text {st }}$ September 2016) 


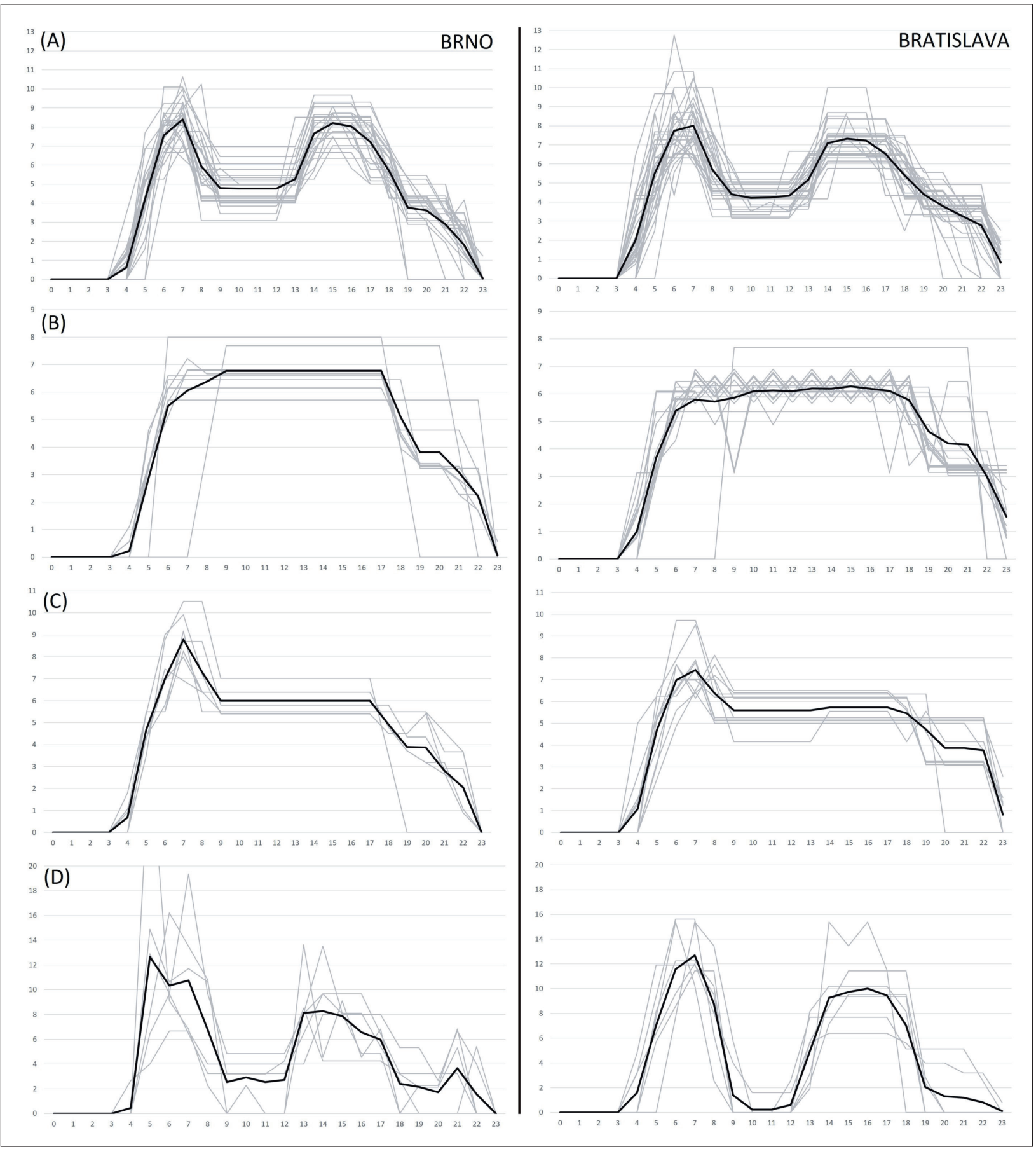

Fig. 7: The distribution of the relative number of connections of public transport lines on a workday according to line types ( $A$ - peak, $B$ - homogeneous, $C$ - morning, $D$ - industrial)

Sources: Public transport timetables in Brno and Bratislava (both valid on $1^{\text {st }}$ September 2016)

during the gap does not decrease more than by one half as opposed to the peaks. There are 27 peak lines in Brno offering 2,264 connections (42.7\% of all connections) and in Bratislava, there are 31 peak lines offering 2,391 connections (41.0\% of all connections). From the point of view of the dominant line type, it is possible to conclude that both cities have almost identical rhythmicity.

The second most frequent type was represented by lines with a homogeneous distribution of connections (B). These are lines with a flat long maximum during most of the daylight hours. Their rhythmic profile rises quickly to reach its daily maximum and keeps it for most of the day to fall a in a relatively gradual way during evening hours. While in Brno, there are 10 lines with 1,094 connections (20.6\% of all connections) of type B, in Bratislava, it is 19 lines with 1,678 connections ( $28.8 \%$ of all connections). There is a significant difference between the two cities in this rhythm. In Bratislava, lines of this type are more common as far as their number and number of connections are concerned, and they have a lower frequency of connections (one connection less per hour than in Brno). They also tend to operate at a higher frequency longer in the evening than in Brno.

The third most represented type consists of lines with a profile of so-called morning rhythm (C). These lines have only one maximum, which comes during the morning peak hours. They quickly rise to a high number of connections per hour (8-9\% of all its daily connections), and then drop 


\begin{tabular}{|c|c|c|c|c|c|c|c|c|c|c|c|}
\hline \multirow{3}{*}{$\begin{array}{l}\text { Type } \\
\text { ID }\end{array}$} & \multirow{3}{*}{ Line type } & \multicolumn{5}{|c|}{ Brno } & \multicolumn{5}{|c|}{ Bratislava } \\
\hline & & \multicolumn{3}{|c|}{ Lines } & \multicolumn{2}{|c|}{ Connections } & \multicolumn{3}{|l|}{ Lines } & \multicolumn{2}{|c|}{ Connections } \\
\hline & & Line ID & Abs. & $\begin{array}{l}\text { Rel. } \\
{[\%]}\end{array}$ & Abs. & $\begin{array}{l}\text { Rel. } \\
{[\%]}\end{array}$ & Line ID & Abs. & $\begin{array}{l}\text { Rel. } \\
{[\%]}\end{array}$ & Abs. & $\begin{array}{l}\text { Rel. } \\
{[\%]}\end{array}$ \\
\hline A & Peak & $\begin{array}{l}27,30,31,32,34, \\
36,37,40,41,43, \\
44,46,49,50,52, \\
53,55,57,58,60 \\
61,63,65,67,69, \\
70,71\end{array}$ & 27 & 35.5 & 2,264 & 42.7 & $\begin{array}{l}33,64,211,21,23, \\
28,30,31,32,37,53 \\
56,57,63,65,66,67 \\
68,70,77,78,83,84 \\
88,90,93,94,95,98 \\
525,801\end{array}$ & 31 & 28.4 & 2,391 & 41.0 \\
\hline B & Homogeneous & $\begin{array}{l}2,4,5,6,11,25 \\
38,76,78, \mathrm{FU}\end{array}$ & 10 & 13.2 & 1,094 & 20.6 & $\begin{array}{l}1,2,3,4,5,6,8 \\
9,210,39,51,54 \\
50,69,87,91,99 \\
123,139\end{array}$ & 19 & 17.4 & 1,678 & 28.8 \\
\hline $\mathrm{C}$ & Morning & $1,3,8,9,26,35,39$ & 7 & 9.2 & 831 & 15.7 & $\begin{array}{l}201,202,203,204 \\
205,207,208,209 \\
212,61,96\end{array}$ & 11 & 10.1 & 945 & 16.2 \\
\hline $\mathrm{D}$ & Industrial & $\begin{array}{l}10,47,54,75,77, \\
\text { MO }\end{array}$ & 6 & 7.9 & 343 & 6.5 & $\begin{array}{l}7,52,74,75,80 \\
191,196\end{array}$ & 7 & 6.4 & 374 & 6.4 \\
\hline \multirow[t]{4}{*}{$\mathrm{E}$} & Afternoon & $12,33,42,64, \mathrm{AV}$ & 5 & 6.6 & 480 & 9.1 & & & & & \\
\hline & Unclassified & $48, \mathrm{OL}$ & 2 & 2.6 & 90 & 1.7 & $24,43,44,92$ & 4 & 3.7 & 101 & 1.7 \\
\hline & $\begin{array}{l}\text { Low-frequency } \\
(<20 \text { connections })\end{array}$ & $\begin{array}{l}\text { E50, 68, 73, 74, } \\
\text { E75, 80, 81, 82, 89, } \\
90,91,92,93,94 \\
95,96,97,98,99\end{array}$ & 19 & 25.0 & 196 & 3.7 & $\begin{array}{l}25,26,27,29,35,41, \\
58,59,79,130,133, \\
147,151,153,184, \\
192,901, \mathrm{~N} 21, \mathrm{~N} 29, \\
\text { N31, N33, N34, N37, } \\
\text { N44, N47, N53, N55, } \\
\text { N56, N61, N70, N72, } \\
\text { N74, N80, N91, N93, } \\
\text { N95, N99 }\end{array}$ & 36 & 33.0 & 322 & 5.5 \\
\hline & In total & & 76 & 100 & 5,298 & 100 & & 109 & 100 & 5,829 & 100 \\
\hline
\end{tabular}

Tab. 3: Types of public transport lines with different rhythmicity of connections during a workday Sources: Public transport timetables in Brno and Bratislava (both valid on $1^{\text {st }}$ September 2016)

to $6-7 \%$ of all its daily connections per hour, and remain at this level until 19:00, when they slowly descend to their night minimum. Despite the fact that these lines in Bratislava retain a higher frequency until later hours, this line type has a similar importance for both cities, representing $10 \%$ of all lines and $16 \%$ of all connections.

The fourth type, which is the last classified type that the two cities have in common, consists of lines that are linked to industrial production (D). The industrial type differs greatly between the two cities, which limits its use for comparability. Nevertheless, it represents lines with two pronounced peaks, which differ from the peak type by the fact that the number of connections during the gap drops to almost zero values. In other words, these are lines with (almost) suspended operation. The main difference lies in the fact that while in Bratislava, this type has only two peaks (in the morning and in the afternoon), in Brno a third peak can be found in the evening hours. They are of similar scope in both cities, representing about $7 \%$ of lines and $6.5 \%$ of all connections. Their temporality is different, however, in that the two-phase cycle in Bratislava refers to a one-shift or two-shift work organisation, while the threephase cycle in Brno indicates work organisation into more shifts (see Fig. 7).

The one type which could be identified in only one city, was the afternoon type (E) found in Brno. Its rhythmic profile is to a large extent inversive to the morning type, having only one maximum during the daylight hours - in the afternoon, typically between 15:00 and 18:00. Such a rhythmic profile was not found with any public transport line in Bratislava. In contrast, Brno had 5 lines with 480 connections (9.1\% of all connections) operating in this rhythm. The relative share of connections rises only slowly during the morning hours to reach the average value of $5.5 \%$ of all its daily connections per hour, which happens around 7:00 and is kept at this value until 13:00, when it starts ascending to its maximum of $8 \%$ connections per hour, from which it gradually falls to its minimum reached around midnight (see Fig. 8)

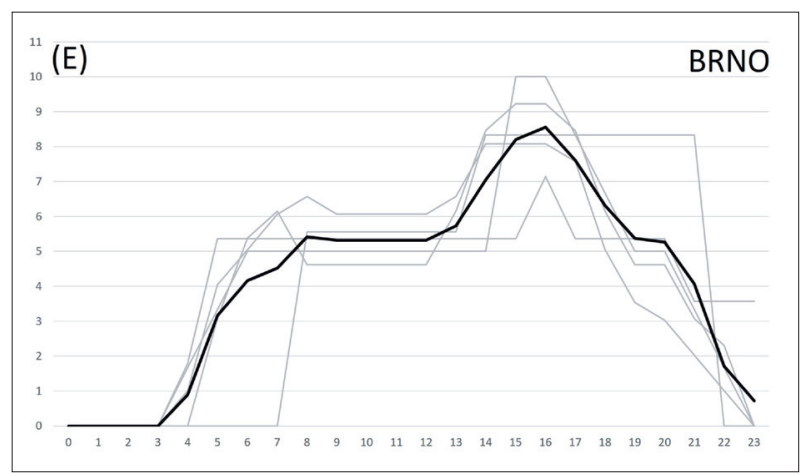

Fig. 8: The distributions of the relative number of connections of the afternoon line type of public transport on a workday in Brno. Sources: Public transport timetables in Brno and Bratislava (both valid on $1^{\text {st }}$ September 2016) 
If we compare the absolute numbers of connections operating for all lines of the designated types in the two cities, we can identify slight rhythmic differences. The biggest disparity is found in the different significance of the homogenous line type, which has a much stronger status in Bratislava than in Brno. To a certain extent, Brno compensates for this difference by the afternoon type of lines. In general, it can also be said that evening transport is organised differently. While in Bratislava all lines are extended until late evening hours and provide for evening transport in a balanced way, Brno counterbalances the evening deficit by a specific industrial line type with a third peak - but this type is limited to a low number of lines (see Fig. 9). The cities also exhibit different rhythmicity in terms of the respective modes of transport: while trams in Bratislava almost solely (with only one exception) belong to the homogeneous type, in Brno they fall under two line types: the homogeneous and the morning type. Thus, it can be said that trams do not contribute to the increase in connections during the afternoon peak in either of the cities, but in Brno they partially feed the morning peak.

Looking at the distribution of line types from a spatial perspective, a comparison of the two cities highlights their different topographies. While Brno is a relatively compact and concentric city, Bratislava is more influenced by its terrain and spreads in several convenient directions further from the centre. This is reflected in their urban times. While Bratislava uses the peak line type to connect more distant suburban areas, Brno concentrates it in the residential areas in the north-west. The homogeneous line type in Brno mostly operates in the central parts of the city, while in Bratislava it is relatively evenly represented in the whole urban area. Similarly, the industrial line type in Brno is mainly limited to the south-eastern part of the city (the largest industrial zone), but in Bratislava, it operates more proportionally around the whole city. On the contrary, the morning lines in Bratislava are concentrated in the central areas, but in Brno they mainly service the housing estates. From the above-mentioned comparisons, it can be concluded that urban time in Brno is more local-specific, while in Bratislava it merges into a heterogeneous urban time with various partial temporal components of the whole city (see Figs. 10 and 11)

\section{Conclusions}

This research project set three goals: empirical, methodological and theoretical. At the empirical level, it can be concluded that both cities and their urban times are very similar, which stems from their analogous population size, similar sociocultural context and a long period of existence within a common state. In the basic comparison, the public transport in Bratislava shows somewhat higher numbers than the public transport in Brno, and it can be said that it has a larger scope. The essential rhythm of the workday is almost identical in both cities with two peaks and one gap in between. The active part in Bratislava is nevertheless longer, thanks to the evening hours, when Bratislava "goes to sleep" more slowly. On a weekend day, Bratislava starts earlier and finishes later than Brno. While Bratislava clearly outnumbers Brno in the absolute number of connections, when comparing the relative average number of connections per line, Brno shows higher values. In general, it can be said that Bratislava offers more lines, which have lower average frequency of connections both on workdays and during weekends, compared to Brno.

Based on a spectral analysis of all lines, four rhythmic types were identified in Bratislava (A-D) and 5 in Brno (adding E): peak (A), homogeneous (B), morning (C), industrial (D) and afternoon (E) types. The largest difference was found between the homogeneous, the industrial and the afternoon types. In Bratislava, the homogeneous lines are much more numerous, as far as their sheer number and their number of connections are concerned, and they are in service even if with a lower frequency of connections per hour in general - until later evening hours. The industrial type of lines in Bratislava have only two peaks (in the morning and in the afternoon), while in Brno they have also a slight evening peak besides these two. The afternoon type of line was identified only in Brno. The urban time in Brno is thus more heterogeneous and local-specific, while in Bratislava, it is more temporally homogeneous in the sense that rhythmic profiles are mixed in the whole city area in a more even manner. Despite the strong similarities of both studied cities, the described differences of urban times reveal the potential for comparative chrono-urbanism, time planning and the time policies of urban spacetime.

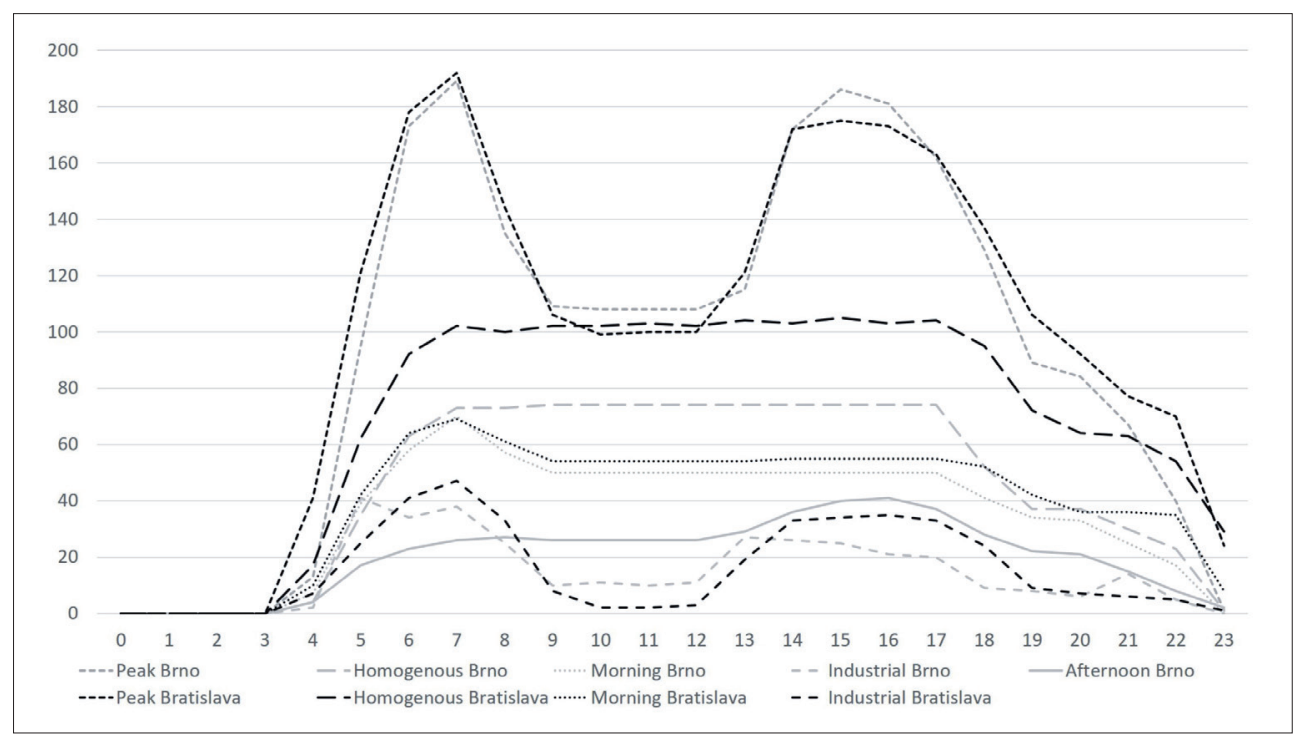

Fig. 9: The distribution of the absolute numbers of all types of public transport connections on a workday Sources: Public transport timetables in Brno and Bratislava (both valid on $1^{\text {st }}$ September 2016) 
At the methodological level, we have presented a concrete procedure for making this comparison. Comparative chronourbanism, as we call it, can be divided into six steps. The first step consists of (i) selecting cities that are comparable, i.e. they have a similar character and the differences in their urban times will not be affected by some radical structural distinctions. The second step means to (ii) operationalise urban time in all compared cities. This operationalisation must be carried out in relation to the available datasets that exist for all cities and that bear some temporal information. Besides datasets with timetables, urban time can be represented by opening times of shops, services and offices, ATM withdrawals or by the amounts of energy consumption in a network.

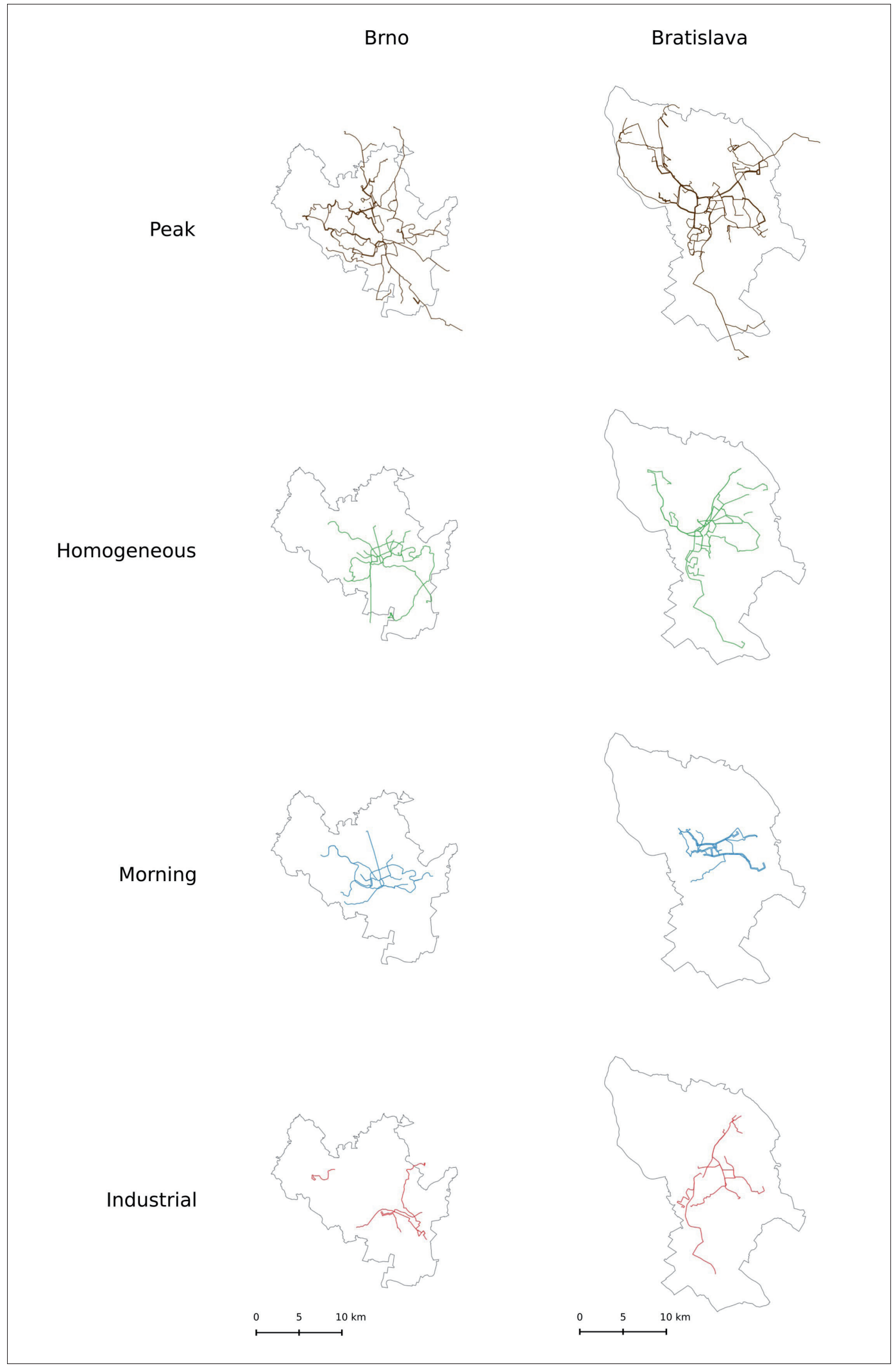

Fig. 10: Spatial analysis of public transport lines according to rhythmic profiles of connections Source: authors' analysis 


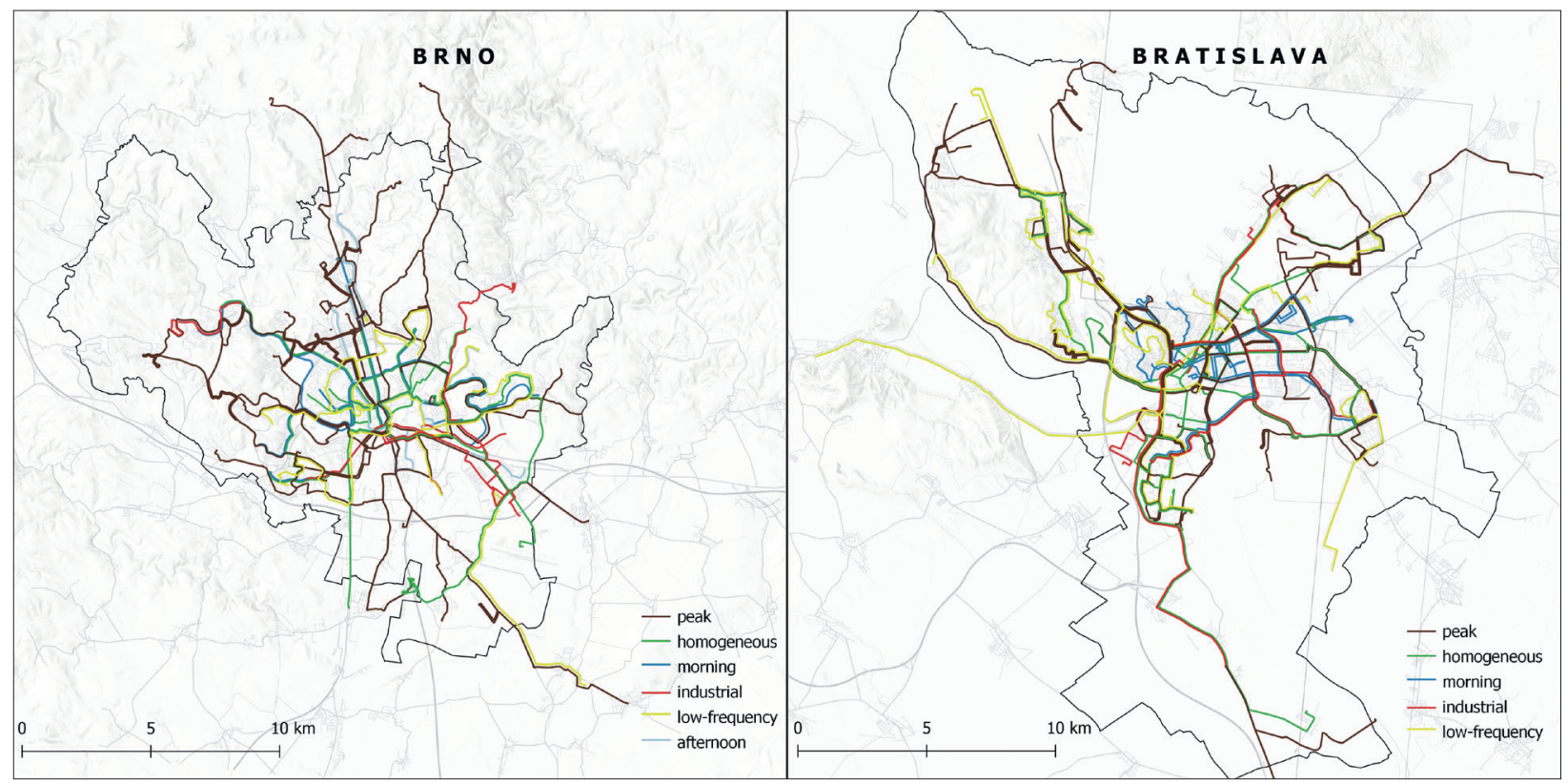

Fig. 11: Spatial synthesis of public transport lines according to rhythmic profiles of connections Source: authors' analysis

The third step (iii) is to analyse the data as a whole, when urban times of the entire cities are compared (Figs. 1, 2, 3, 5). Then, as the fourth step, (iv) the institutional carriers of urban time (in this case, lines of public transport) are analysed. Their time characteristics are visualised in a graphical manner and overall urban time is divided into spectral profiles of a multitude of heterogeneous times. Due to a high number of carriers, the spectral profile of thus construed urban times is difficult to interpret (see Figure 6), and that is why it is necessary to carry out the fifth step and (v) cluster lines into so-called rhythmic types. In this step, rhythmic profiles of the respective institutional carriers of urban times are compared, and based on their similarity, their types are inductively derived (see Figs. 7 and 8). Lines are then divided into these line types and the urban times of cities are compared on the basis of these rhythmic types (see Fig. 9). The last step (vi) restores the spatial dimension of the rhythmic types, and urban times are analysed according to their spatial distribution in the city area (see Figs. 10 and 11). Comparative chrono-urbanism thus makes it possible to compare urban time at three levels: at the level of the whole city, at the level of individual types of urban times, and at the level of the spatial distribution of these urban times. Even in great detail, this process makes it possible to keep a high standardisation of urban time comparisons, which is necessary for applications to a greater number of urban times and which can increase the interest in time policies and urban planning.

At the theoretical level, this paper has explored the possibility of a comparison of time policies of two or more cities at one moment, or one city in two or more time periods. To this end, the article introduces a category of rhythmic types that brings together different carriers of urban time with the same rhythmic profile. The whole complex of urban time is simplified into a few rhythmic profiles and based on them the individual complexes of urban time can be compared with each other. We demonstrate this comparison on the rhythmicity of public transport. It is not a question of capturing one urban time in its complexity, but rather the selection of a suitable carriers of urban time that allows this comparability. Instead of public transport, for example, the opening hours of retail stores, the development of water, gas or electricity consumption, the development of the intensity of financial transactions or the frequency of bank withdrawals, could be compared by analogy.

The theoretical value of comparative chrono-urbanism is not linked to any specific aspect of urban time and at the same time does not lie in capturing the whole complexity of the urban time of a certain city. Its main theoretical value lies in the possibility of comparing one urban time with another and making visible the differences between the urban times of individual cities. The identification and description of these differences is a valuable tool for urban time policies, both for the reflected and especially for the non-reflected. Awareness of the specificity of urban time can help urban planners face the issue of time policies and time planning, and to include the time aspect among the assessed consequences of specific urban decisions.

\section{Acknowledgements}

This work was supported by the Czech Science Foundation (Geography of recycling urban space, 17-26934S) and Scientific Grant Agency VEGA (registration number 1/0049/18). The authors are very grateful for this support.

\section{References:}

ASCHER, F. (1997): Du vivre en juste à temps au chronourbanisme. Les Annales de la recherche urbaine, 77(1): 112-122.

ASCHER, F. (2001): Les nouveaux principes de l'urbanisme. La fin des villes n'est pas à l'ordre du jour. La Tour d'Aigues, Éditions de l'Aube.

ASCHER, F. (2008): Les nouveaux compromis urbains. Lexique de la ville plurielle. La Tour d'Aigues, Éditions de l'Aube.

BALBO, L. (1978): La doppia presenza. Inchiesta, 32: 8-15.

BELLONI, M. C. (1998): Le politiche italiane sui tempi della cittá. Appunti per una rifessione sociologica. In: Paolucci G. [ed.]: La Cittá Macchina del Tempo. (pp. 132148). Milano, Politiche del Tempo Urbano in Italia. 
BONFIGLIOLI, S. (1997): Urban Time Policies in Italy: An Overview of Time-Oriented Research. Transfer:European Review of Labour and Research, 3(4): 700-722.

COCHOY, F., ASCHER, F. (1997): Du vivre en juste à temps au chrono-urbanisme. Les Annales de la recherche urbaine, 77(1): 112-122.

CRANG, M. (2001): Rhythms of the city: Temporalised space and motion. In: May, J., Thrift, N. [eds.]: Timespace: Geographies of Temporality (pp. 187-207). London, Routledge.

DREVON, G., GWIAZDZINSKI, L., KLEIN, O. (2017): Chronotopies, Lecture et écriture des mondes en mouvement. Grenoble, Elya Editions.

FERNANDES, J., CHAMUSCA P. (2014): Urban policies, planning and retail resilience. Cities, 36: 170-177.

GWIAZDZINSKI, L. (2014): The Nocturnal Condition. CoLaboratorio's Managing Group. Night Manifesto. Seeking Citizenshup 24h., CoLaboratorio's Managing Group, 53-70.

GWIAZDZINSKI, L. (2015): The Urban Night: A Space Time for Innovation and Sustainable Development. Articulo Journal of Urban Research, 11: 1-14.

GWIAZDZINSKI, L., MAGGIOLI, M., STRAW, W. (2018): Géographies de la nuit. Geografie della notte. Bollettino della Società Geografica Italiana serie 14, 1(2): 3-8.

HAGBERG, J., CANU, R. (2015): The forgotten role of pedestrian transportation in urban life: Insights from a visual comparative archaeology (Gothenburg and Toulouse, 1875-2011). Urban Studies, 52(12): 2267-2286.

HARMOINEN, L. (2003): Time-Geografical Authority Constraint and Allocation of Time between Workplace and Home. Diploma thesis. Helsinki, University of Helsinki.

HUTCHINGS, K. (2008): Time and World Politics: Thinking the Present. Manchester, Manchester University Press.

JOHANSSON, M., KOCIATKIEWICZ, J. (2011): City festivals: creativity and control in staged urban experiences. European Urban and Regional Studies, 18(4): 392-405.

KÄRRHOLM, M. (2009): To the rhythm of shopping - on synchronisation in urban landscapes of consumption. Social \& Cultural Geography, 10(4): 421-440.

KÄRRHOLM, M. (2012): Retailising Space. Architecture, Retail and the Territorialisation of Public Space. Surrey, Ashgate.

KÄRRHOLM, M., BARATA-SALGUEIRO, T., SOUMAGNE, J., FERNANDES, J., CHAMUSCA, P. (2017): Time-space complexity and the opening hours of commerce: a study of four European cities. Revista de Geografia e Ordenamento do Território (GOT), 12: 153-177.

KLINKE, I. (2013): Chronopolitics: A Conceptual Matrix. Progress in Human Geography, 37(5): 673-690.

LAGUERRE, M. (2003): Urban Multiculturalism and Globalization in New York City: An Analysis of Diasporic Temporalities. New York, Palgrave Macmillan.

LAGUERRE, M. (2004a): The Muslim chronopolis and diasporic temporality. In: Krase, J., Hutchison, R. [eds.]: Race and Ethnicity in New York City. Research in Urban Sociology, 7: 57-81. Bingley, Emerald Group Publishing Limited.
LAGUERRE, M. (2004b): Virtual time: the processuality of the cyberweek. Inform. Commun. Soc. 7(2): 223-247.

LAGUERRE, M. (2007): Diasporic globalization: reframing the local/global question. Ethnic Landscapes Urban World 8: 15-40.

LAGUERRE, M. (2010): A cosmonational theory of global neighborhoods. Amerasia J., 36(3): xv-xxxiv.

LEVINE, R. (1997): A geography of time: The temporal misadventures of a social psychologist. New York, BasicBooks.

MAREGGI, M. (2002): Innovation in Urban Policy: The Experience of Italian Urban Time Policies. Planning Theory \& Practice, 3(2): 173-194.

MULÍČEK, O., OSMAN, R. (2018): Rhythm of urban retail landscapes: Shopping hours and the urban chronotopes. Moravian Geographical Reports, 26(1): 2-13.

MULÍČEK, O., OSMAN, R., SEIDENGLANZ, D. (2010): Časoprostorovérytmy města-industriálnía postindustriální Brno. In: Ferenčuhová, S., Galčanová, L., Vacková, B. [eds]: Československé město včera a dnes: každodennost, reprezentace, výzkum (pp. 195-220). Červený Kostelec, Brno, Pavel Mervart/Masarykova univerzita.

MULÍČEK, O., OSMAN, R., SEIDENGLANZ, D. (2015): Urban rhythms: a chronotopic approach to urban timespace. Time \& Society, 24(3): 304-325.

MULÍČEK, O., OSMAN, R., SEIDENGLANZ, D. (2016): Time-space rhythms of the city - The industrial and postindustrial Brno. Environment and Planning A, 48(1): 115-131.

OSMAN, R., MULÍČEK, O. (2017): Urban chronopolis: Ensemble of rhythmized dislocated places. Geoforum, 85: 46-57.

OSMAN, R., MULIIČEK, O., SEIDENGLANZ, D. (2019): Regional heteroglossia: the metropolitan region as a dialogical landscape. European Planning Studies, 27(11): 2079-2098.

PAFKA, E. (2013): Places as intersecting flows: mapping urban morphologies, functional constellations and pedestrian rhythms. In: $4^{\text {th }}$ Global Conference: Space and Place. Oxford, Mansfield College.

PARKES, D., THRIFT, N. (1978): Putting Time in Its Place. Making Sense of Time, 1: 119-129.

PARKES, D., THRIFT, N. (1980): Times, Spaces, and Places: A Chronogeographic Perspective. Chichester, John Wiley \& Sons.

RÄMÖ, H. (1999): An Aristotelian Human Time-Space Manifold: From Chronochora to Kairotopos. Time \& Society, 8(2): 309-328.

SCHWANEN, T., VAN AALST, I., BRANDS, J., TIMAN, T. (2012): Rhythms of the night: spatiotemporal inequalities in the nighttime economy. Environment and Planning A, 44(9): 2064-2085.

WUNDERLICH, F. M. (2007): Symphonies of Urban Places: Urban Rhythms as Trace of Time in Space. Place and Location: Studies in Environmental Aesthetics and Semiotics, 6: 91-111.

WUNDERLICH, F. M. (2008): Walking and Rhythmicity: Sensing Urban Space. Journal of Urban Design, 13(1): 125-139. 
WUNDERLICH, F. M. (2010a.): The Aesthetics of PlaceTemporality in Everyday Urban Space: the Case of Fitzroy Square. In: Edensor, T. [ed.]: A Geography of Rhythms (pp. 45-56). London, Ashgate.

WUNDERLICH, F. M. (2010b): Place-Temporality in Urban Analysis and Design: Uncovering Place-Temporal Aesthetics through the Means of Rhythm at Fitzroy Square, Ph.D. thesis. London, University College London.
WUNDERLICH， F. M. (2013): Place-temporality and urban place-rhythms in urban analysis and design: An aesthetic akin to music. Journal of Urban Design, 18(3): 383-408.

\section{Please cite this article as:}

OSMAN, R., IRA, V., TROJAN, J. (2020): A tale of two cities: The comparative chrono-urbanism of Brno and Bratislava public transport systems. Moravian Geographical Reports, 28(4): 269-282. Doi: https://doi.org/10.2478/mgr-2020-0020 